\title{
LA ILUSTRACIÓN. Y POR QUÉ SIGUE SIENDO IMPORTANTE PARA NOSOTROS
}

\author{
Anthony Padgen \\ (2015) Alianza Editorial \\ Madrid, 542 pp.
}

\author{
Carlos Alonso Mauricio \\ Universidad Carlos III de Madrid \\ caralons@der-pu.uc3m.es
}

DOI: http://dx.doi.org/10.20318/eunomia.2016.3302

\begin{abstract}
El libro de Padgen no se nos presente como una simple monografía dedicada a estudiar de manera concreta aquellos aspectos más relevantes del pensamiento de la llustración, haciendo un análisis más o menos general de las conclusiones alcanzadas y refiriendo una breve relación de autores representativos. Todo lo contrario. Nos encontramos ante un trabajo que encierra un saber enciclopédico y un abrumador conocimiento de autores y obras que queda reflejado en las continuas citas que realiza el autor, acompañado todo ello de un profundo conocimiento de las relaciones personales y la correspondencia sostenida por algunos de los más influyentes pensadores de occidente.
\end{abstract}

El objetivo del libro no parece ser transmitir al lector con claridad y concisión la relevancia de esta época de la historia del conocimiento a través de una detallada explicación de los descubrimientos o avances logrados por los pensadores que la desarrollaron, sino que se nos presenta una narración ágil y estructurada en una forma casi dialógica entre los grandes pensadores de la ilustración. Los temas y los problemas se suceden en una secuencia de propuestas y opciones diferentes en función de la época de su producción y del autor de las mismas. Es, en definitiva, una obra que asume plenamente la filosofía ilustrada de la crítica racional como leitmotiv de su narración y nos conduce a descubrir la complejidad y riqueza de una época fundamental de la historia de las ideas y fundacional del occidente que hoy vivimos. La llustración no es un proceso lineal de avance del conocimiento científico, social o político, sino un periodo de encuentro, enfrentamiento y cambio de la forma de ver y enfrentarse a la realidad del momento y, en definitiva, "la llustración nos importa aún porque nosotros, los europeos occidentales, somos herederos suyos. Por tanto, no es ocioso que aspiremos a comprenderla en profundidad" (Padgen, 2015, p. 12).

La llustración, como evidencia Padgen en su obra, es una época determinada por la insumisión intelectual a las verdades preexistentes, al método 
escolástico y a la colonización del conocimiento por parte de la teología. El descubrimiento de América y la quiebra de la unidad de la fe en Europa con la Reforma, debilitaron la posición hegemónica de los teólogos escolásticos en el pensamiento filosófico y esta situación fue, finalmente, el punto de partida de una forma de pensar que cambiaría el mundo.

Pero, como afirma el autor, estos dos acontecimientos, a saber, la ampliación del mundo conocido y la ruptura de la unidad de la fe, siendo relevantes, no explican por sí solos la pérdida de la influencia intelectual de la escolástica y la teología y la aparición de la nueva forma de pensamiento ilustrada. "Lo que al final acabó con el poder y el crédito de la Iglesia católica y de todas las iglesias no fue la Reforma, sino las terribles guerras de religión que se produjeron" (p. 62). La caída de la Iglesia como institución de referencia intelectual de la sociedad europea hizo desaparecer todas las certezas, no sólo religiosas, sino también morales y políticas sobre las que las sociedades europeas se habían organizado. Era necesario encontrar otros argumentos distintos y alejados de la revelación o la divinidad para justificar la convivencia social, las formas de gobierno, el mismo derecho o los métodos de investigación vigentes hasta el momento. Aparece entonces el germen del pensamiento ilustrado, el recurso a la razón.

Expone en este momento Padgen el surgimiento de la teoría del derecho natural moderno, alejado, más bien, apartado de los principios que lo habían regido en los últimos siglos, es decir, separado de la idea de Dios, y de la idea de la revelación como forma de conocimiento de su contenido (pp. 72 y ss.). La secularización del derecho natural implicó necesariamente la separación del principio de sociabilidad de sus antecedentes teológicos, es decir de Santo Tomás de Aquino y su antecedente clásico Aristóteles y sus ideas de sociabilidad natural ( $p$. 91), para situarlo en el plano de la necesidad, más bien, la conveniencia o la mera tendencia a la unión social, surgía así el concepto de estado de naturaleza y la teoría contractualista para explicar el origen de las sociedades y de las formas de gobierno (pp. 94 y ss.).

En la obra se abordan con un prolijo análisis de títulos relevantes y autores imprescindibles otros muchos temas fundamentales que ocuparon el pensamiento ilustrado y que algunos de ellos, aún hoy, siguen estando vigentes en el debate teórico y político contemporáneo. Encontramos el debate sobre cuáles son las fuentes esenciales que influyeron en los pensadores ilustrados, apareciendo el estoicismo como una teoría fundamental para entender los conceptos de sociabilidad, de ley de cosmopolitismo y, sobre todo, de razón. Siguiendo, a continuación, las reflexiones sobre el papel de la religión en relación a la moral social o, incluso, a la política. Relata Padgen la contestación de los ilustrados contra los dogmas de la Iglesia, el estudio y sometimiento de los mismos a la crítica racional y la exigencia de la separación de la moral religiosa de la política y la ética de la sociedad (pp. 127 y ss.)

También se investigan las aportaciones de los ilustrados al estudio del método de las ciencias naturales y su posible aplicación al estudio mismo del ser humano, la creación de una "ciencia del hombre" que incluía la reflexión sobre la esencia del hombre, es decir, aquellos atributos que nos hacen acreedores de la pertenencia a un mismo grupo humano, reflexión heredada del cosmopolitismo estoico, y que obligó a abordar, por ejemplo, la cuestión de la esclavitud y la relación entre los europeos y los pueblos indígenas, salvajes en los términos del momento. Existía, ya desde el siglo XVII, pero fundamentalmente en la época ilustrada una "necesidad acuciante de comprender científicamente al hombre" (pp. 182 y ss.) 
A este debate contribuyó extraordinariamente el surgimiento de una nueva corriente literaria, los libros de viajes, que tuvo un extraordinario acogimiento pero que, de hecho, la mayoría de los philosophes consideraba inferior al conocimiento especulativo que éstos cultivaban. En este sentido podemos encontrar el desarrollo de teorías tendentes a justificar las diferencias sociales entre los distintos grupos observados en el mundo basadas en cuestiones tales como el clima, las costumbres, las tradiciones o usos sociales entre otras, todas ellas encaminadas a argumentar la existencia de un concepto universal de humanidad y, por tanto, la imposibilidad de calificar a los grupos humanos unos como inferiores y otros como superiores, teorías éstas surgidas, fundamentalmente, en el siglo XIX (pp. 233 y ss.). También podemos encontrar en relación a la homogeneidad del género humano una interesante, profunda y eminentemente actual reflexión sobre el origen del pensamiento feminista en este periodo histórico, reconociendo muchos de los grandes autores la inconsistencia de los argumentos que sostenían la inferioridad del sexo femenino al tiempo que, por otra parte, destacadas mujeres, pertenecientes en exclusiva a la élite intelectual y económica fundamentalmente francesa, comenzaron a destacar y a ocupar posiciones relevantes en sus sociedades (pp. 294 y ss.).

Toda esta amplísima variedad de discusiones, reflexiones y debates surgidos y sostenidos en la llustración se podían enmarcar en uno mucho más amplio y general que sería, en definitiva, la incesante búsqueda de un modelo de civilización, de sociedad civilizada y la pretensión de identificarla con la sociedad europea ilustrada, en contraposición al resto de formas de organización social observadas en otras partes del Planeta como África, las sociedades indígenas de América o los pueblos descubiertos en el Pacífico. Ahora bien, como nos informa Padgen, surge un extraordinario debate en relación a la gran civilización del lejano oriente, cada vez más conocida y estudiada, que era China. Podemos encontrar a destacados intelectuales panegiristas de la civilización China que elogiaban y, de hecho, consideraban superior la estructura moral de la sociedad oriental a la europea, así como muy relevantes autores que desarrollaban lecturas opuestas respecto de esta sociedad, como era el caso de Montesquieu, quien basándose en una división de las formas de gobierno de origen clásico, consideraba a China un modelo de despotismo, muy alejado del ideal republicano mixto entre la democracia y la aristocracia (pp. 301 y ss.).

El objetivo final, último, del periodo ilustrado y la meta a la que, ineluctablemente, les conducían sus reflexiones era a plantear la existencia de un concepto común de humanidad y de una idea de patria superior al concepto conocido de nación. De este modo, sobre la base del concepto de patria cosmopolita desarrollado por el estoico Cicerón, comienzan a construir "lo que podríamos calificar de patriotismo cívico moderno. Bondadoso, generoso, amplio de miras" y con un referente claro, la humanidad en su conjunto, que hace superar las lealtades hacia la familia, la comunidad o la nación en la que vivimos para mirar más allá de nuestras propias, y estrechas, fronteras y conseguir una norma de conducta que tenga como verdadera finalidad el bien común de la humanidad en su conjunto. Esto es a lo que, posteriormente Immanuel Kant llamaría "patriotismo mundial" (pp. 325 y ss.). Esta era la verdadera ambición de la llustración, "crear una ciencia humana históricamente fundamentada que facilitara la llegada de una civilización universal, capaz de hacer de los seres humanos individuos independientes, autónomos, libres de los dictados que vengan desde arriba o desde abajo, conocedores de sí mismos y dependientes sólo los unos de los otros para sobrevivir" (p. 403). 
Pero al periodo ilustrado no le han faltado detractores y contestaciones a lo largo de los siglos siguientes y, precisamente a sus "enemigos" dedica Padgen el último capítulo de su libro (pp. 405 y ss.). Ya desde épocas muy cercanas a la propia llustración podemos encontrar críticas feroces al periodo y a las, supuestas, consecuencias del mismo, achacando al pensamiento ilustrado la forma de entender el mundo que llevó a la Revolución Francesa a la instauración del terror por parte de Robespierre y su concepto de razón y virtud. Más allá de estas primeras críticas no han faltado autores representativos, destacando entre ellos, por ejemplo, Alasdir Maclntayre, que han acusado a la llustración de separar al individuo de todo sustrato moral, abandonándole al debate estrictamente racional produciendo así "una cultura falta de dirección y de metas" (p. 430).

Al terminar el libro completo cobra sentido su título, la reflexión inicial sobre la importancia que tiene aún hoy la llustración para nosotros termina aclarándose cuando el lector, finalmente, se percata de que este periodo histórico no nos aporta certezas y conceptos concretos, no nos sirve para resolver todas nuestras dudas 0 , si quiera, para hacer nuestra convivencia social más sencilla, sino que su importancia está en habernos dotado un método de entender e investigar el mundo, su importancia radica en haber ampliado las fronteras del conocimiento y la conciencia humanas y, sin duda, en haber definido los conceptos que aún hoy estructurado nuestra propia cosmovisión, las ideas de libertad, de individuo, de razón, de humanidad, de moral, y tantas otras, cambiaron en este periodo histórico fundamental, y con ellas, cambió el mundo en el que hoy seguimos viviendo. 